\title{
Helminth parasites in the intestinal tract of indigenous poultry in parts of Kenya
}

\author{
L W Irungu ${ }^{a^{*}}$, R N Kimani ${ }^{a}$ and S M Kisia ${ }^{\mathrm{b}}$
}

\begin{abstract}
A study was carried out on 456 indigenous poultry intestinal specimens from various towns in Kenya to determine the occurrence and distribution of helminth parasites in the intestinal tract of the birds. Of the specimens examined, 414 had parasites whereas the remaining 42 had none, which is an infection rate of $90.78 \%$. The main species of helminths found in the intestines were Raillietina sp. (47.53\%), Heterakis gallinarum (21.33\%), Ascaridia galli $(10.03 \%)$, Strongyloides avium (9.96\%), Choanotaenia infundibulum (4.61\%), Cotugnia digonopora (3.6\%), Capillaria sp. (1.5\%), Trichostrongylus tenius (1.04\%) and Syngamus trachea $(0.40 \%)$. Most helminths were present in both the mid- and hindguts. Syngamus trachea and C. digonopora were only found in the foregut and midgut, respectively. Although chickens from which the specimens were collected appeard healthy, the high prevalence of helminthiasis observed shows the poor level of helminth infection control practiced by the indigenous poultry keepers in the country, which might affect the health status of the birds and their growth rates. Poultry keepers should be encouraged to prevent, control and treat such cases.
\end{abstract}

Key words: helminths, indigenous poultry, Kenya.

Irungu L W, Kimani R N, Kisia S M Helminth Parasites in the intestinal tract of indigenous poultry in parts of Kenya. Journal of the South African Veterinary Association (2004) 75(1): 58-59 (En.). Department of Zoology, University of Nairobi, PO Box 30197, Nairobi, Kenya.

\section{INTRODUCTION}

Indigenous poultry, which account for about $70 \%$ of the Kenyan poultry population, are kept by a majority of the rural population under the free-range system of production. Indigenous poultry are a major source of protein and income to the population as they are hardier than the exotic faster-growing and more productive breeds of poultry. That helminthiasis, though not clinically manifested, contributes to production losses in the poultry industry in developing countries is becoming more apparent ${ }^{2}$. Several studies have been carried out on free-ranging poultry and the prevalence of gastrointestinal parasites in the region. A study on rural, scavenging chicken from Morogoro, Tanzania ${ }^{6}$ found that all of the 600 chickens examined were infected with 1 or several species of helminths with an average number of helminths per bird of $4.8 \pm 1.7$ during the wet seasons and $5.1 \pm$ 1.8 during the dry season. Other studies ${ }^{3,5}$ showed infection prevalences of $88 \%$ for roundworms in Leku, southern Ethiopia,

aDepartment of Zoology, University of Nairobi, PO Box 30197, Nairobi, Kenya.

${ }^{b}$ Department of Veterinary Anatomy, University of Nairobi, PO Box 30197, Nairobi, Kenya.

*Author for correspondence. E-mail: lirungu @ uonbi.ac.ke Received: September 2003. Accepted: February 2004. and $93.5 \%$ for mixed infections from Dschang market in western Cameroon, respectively.

The type of management system adopted greatly influences the parasitic load of poultry. It has been shown that chickens reared under the cage system gave negative results for helminth parasites whereas free-ranging chickens had the highest helminth infection rate ${ }^{1}$. Most of the helminth parasites were nematodes.

The present study was undertaken to establish the prevalence of helminthiasis in free-ranging indigenous poultry as it contributes to poor poultry productivity, which affects the small scale farmer. The study was to serve as a database on the most common helminths in indigenous poultry. This is important in controlling the prevalence of helminthiasis.

\section{MATERIALS AND METHODS}

Intestinal samples of 456 indigenous poultry were collected from Kariokor Market, Nairobi. Poultry from various parts of the country are collected and slaughtered there. The samples were separated into foregut, midgut and hindgut, using ligatures, labelled and preserved in $10 \%$ neutral buffered formalin. The sample sections were later opened using scissors and their contents washed into Petri dishes using normal saline. The worms were stored in bottles, fixed in $70 \%$ ethanol and then stored in $10 \%$ formalin before identification. The worms were identified using dichotomous keys ${ }^{7,8}$. Microscopic examination of faeces for helminth eggs was done at $\times 40-60$ magnification after making a direct smear of the faeces or after filtering the faeces in normal saline through a cheese cloth and centrifuging the contents ${ }^{4}$.

\section{RESULTS}

Out of a total of 456 specimens observed in the study, 414 were found to be positive whereas 42 were negative for helminthiasis, giving a prevalence rate of $90.78 \%$. The specimens used in the study came from chickens derived from various towns in Kenya, including Nairobi, Machakos, Kitui, Makueni, Nyahururu and Bomet. Their infection rates are shown in Fig. 1. Birds examined from Nairobi, Machakos and Nyahururu were all infected with helminthes whereas those from Bomet had the lowest prevalence rate $(86.57 \%)$.

The most prevalent helminths were Raillietina sp. (47.53\%), Heterakis gallinarum (21.33\%), Ascaridia galli (10.03\%), Strongyloides avium (9.96\%), Choanotaenia infundibulum (4.61\%), Cotugnia dignopora (3.6\%), Capillaria sp. (1.51\%), Trichostrongylus tenius $(1.04 \%)$ and Syngamus trachea $(0.40 \%)$.

Various helminth eggs observed in the faeces included those of Heterakis gallinarum (47.5\%), Ascaridia galli $(27.7 \%)$, Capillaria $(12.8 \%)$ and Trichostrongylus tenius $(12.0 \%)$.

Most of the helminths were found in the mid- and hindguts with the exception of C. dignopora and T. tenius which were present only in the mid- and hindguts, respectively, and $S$. trachea which was the only helminth found in the foregut. The latter usually inhabits the respiratory tract.

\section{DISCUSSION}

The method used in the present study to quantify the level of helminthiasis is reliable as helminths were observed di- 


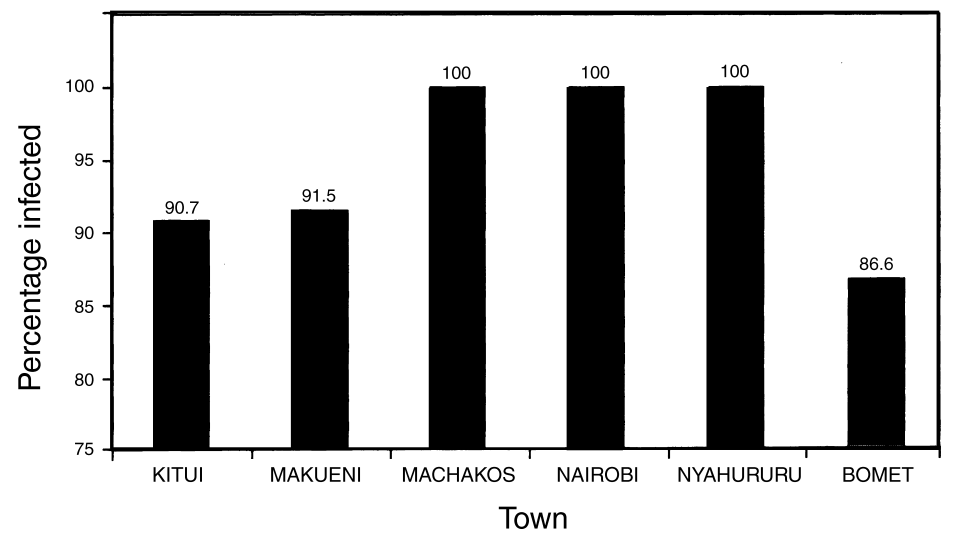

Fig. 1: Percentage infected specimens from various towns in Kenya.

rectly whereas many cases of helminthiasis go unnoticed since clinical symptoms are often undetected. Diagnosis of worm infections by examination of fresh droppings for presence of eggs or segments is also unreliable even in some cases of heavy infection. Although the present study only covers a small area of Kenya where indigenous poultry occur, it does give an indication of the level of helminthiasis in several parts of the country. In Nairobi, Machakos and Nyahururu, the $100 \%$ positive cases could be attributed to the small number of specimens examined (fewer than 20 from each town), which made it less likely that negative cases would be found. By contrast, from Makueni (91.46\% prevalence), 150 specimens and from Bomet $(86.59 \%$ prevalence), 116 specimens were examined. Generally, a high percentage of helminthiasis was observed in the present study. This may pose a major problem to the small scale poultry farmers by lowering productivity in the industry. The helminths compete for nutrients with the host and also cause inflammation and lesions in the intestinal tract that interfere with digestion and assimilation of nutrients by the host.

In the absence of control of the parasites and treatment of infected birds, a high helminth load is to be expected in freeranging poultry as the intermediate hosts of the helminths are normally ingested by the poultry. For example, the larval form of Railletinia sp. is found in various intermediate hosts such as ground and dung beetles as well as ants, and the larval stage of H. gallinarum is found in earthworms. Nematodes were the most common helminths. Seven species of nematodes were identified whereas only 2 species of cestodes were seen. Trematodes were not observed in the study as snails and fish serve as intermediate hosts. Poultry are found in the homestead and rarely have access to aquatic conditions, which are habitats of these intermediate hosts.

A control measure that can greatly reduce the helminth load in poultry is one that interferes with the life cycle of the parasite. The intermediate host should not have access to the faeces of poultry since free-ranging poultry will eventually feed on potential intermediate hosts. Although the disposal of poultry droppings is unquestionably the most important preventive measure towards the control of helminth infestation because faeces is the source by which intermediate hosts become infected, this is not applicable in a rural setting. Such drop- pings can be spread out thinly on land out of reach of poultry or in places rarely frequented by poultry. The dehydrating effect of the sun and wind on the droppings will quickly destroy the parasitic material in the droppings and the droppings will also enrich the land as a fertiliser. Such a practice can be accompanied by rotation of the birds from one area to another in order to reduce parasitism among birds.

\section{ACKNOWLEDGEMENTS}

This study was funded by a grant from the Kenya Agricultural Research Institute (KARI). We thank Mr Nicodemus Muia for technical assistance.

\section{REFERENCES}

1. Abebe W, Asfaw T, Genete, B, Kassa B, Dorchies P 1997 Comparative studies of external parasites and gastrointestinal helminths of chickens kept under different management systems in and around Addis Ababa (Ethiopia). Revue de médecine vétérinaire 22: 497-500

2. FAO (1992) Distribution and impact of helminth diseases of livestock in developing countries. FAO animal production and health paper 96. Food and Agricultural Organization of the United Nations

3. Mpoame M, Agbede G 1995 The gastrointestinal helminth infections of domestic fowl in Dschang, Western Cameroon. Revue élevage et de médecine vétérinaire des pays tropicaux. 48: 2, 147-51

4. Muller R 1975 Worms and disease. A manual of medical helminthology. William Heineman Medical Books, London. 136-137

5. Negesse T 1993 Prevalence of diseases, parasites and predators of local chickens in Leku, Southern Ethiopia. Bulletin of Animal Health and Production in Africa 33: 317-321

6. Permin A, Magwisha H, Kassuku A A, Nanssen P, Bisgaard M, Frandsen F, Gibbons L 1997 A cross sectional study of helminths in rural scavenging poultry in Tanzania in relation to seasons and climate. Journal of Helminthology 21: 233-240

7. Yamaguti S 1959 Systema Helminthum Vol. II. The cestodes of vertebrates. Interscience Publishing, New York

8. Yamaguti S 1961 Systema Helminthum Vol. III. The nematodes of vertebrates part I and II. Interscience Publishing, New York 